\title{
Condições de treino e sistemas de categorização de verbalizações de terapeutas ${ }^{1}$
}

\section{Training conditions and evaluation of systems of categorization of therapists' speech}

\author{
Emmanuel Zagury Tourinho², Simone Neno, Jussara Rocha Batista, \\ Mariana Gaspar Garcia, Gisele Gillet Brandão, Lívia Melo Souza, \\ Juliana Bentes de Lima, João Ilo Coelho Barbosa, \\ Peter Endemann e Michele Oliveira-Silva. \\ Faculdade de Psicologia, Universidade Federal do Pará.
}

\begin{abstract}
Resumo
A difusão da terapia verbal de base analítico-comportamental deu origem a uma agenda de investigações em análise do comportamento, com o objetivo de especificação de algumas de suas dimensões. O presente artigo apresenta um percurso de investigação, com vistas ao desenvolvimento de uma metodologia para a análise de verbalizações (respostas verbais vocais) de terapeutas em terapia analíticocomportamental. São descritos cinco estudos que avaliaram condições de treino e um sistema para a categorização de verbalizações de terapeutas, baseado em possíveis funções básicas dessas verbalizações. A qualidade do sistema foi avaliada aferindo-se o índice de concordância entre categorizadores. Nos estudos, foram manipuladas variáveis como características do sistema de categorização, experiência do categorizador com a tarefa, familiaridade do categorizador com a categorização por outros, tipo e quantidade de treino e complexidade das sessões. Os resultados mostram que: a) o treino favorece índices de concordância muitas vezes superiores a $70 \%$, sugerindo certa consistência do sistema de categorização; b) os índices de concordância são mais elevados para as categorias Investigar e Confrontar e uma maior proporção destas no conjunto das verbalizações categorizadas explica os melhores índices de concordância alcançados; c) o processo de aferição da concordância por comparação das categorizações de categorizadores pode resultar em índices que não refletem a qualidade do sistema de categorização. Características do material categorizado e do processo de categorização são apontadas como obstáculos para que sejam alcançados índices de concordância superiores a 70\% e como indicação de que aspectos metodológicos podem explicar índices elevados alcançados em alguns estudos.
\end{abstract}

Palavras-chave: Terapia analítico-comportamental, Comportamento verbal de terapeutas, Categorização de verbalizações.

\begin{abstract}
The dissemination of behavior-analytic verbal therapy gave rise to a set of investigations in behavior analysis, towards the specification of some of its dimensions. This article presents a course of investigation that aimed to develop a methodology to be used in the analysis of therapists' verbalizations (vocal verbal responses) in behavior-analytic therapy. The article presents five studies that evaluated a system for categorization of therapists' verbalizations, based on their possible basic functions. The quality of the system was assessed through an index of agreement between participants. Variables manipulated in the studies included characteristics of the categorization system, experience of the participants with the task, familiarity of participants with others' categorization, type and amount of training, and complexity of the sessions. Results showed that: a) training favors indexes of agreement often higher than $70 \%$, which suggest that the system of categorization is somewhat consistent; b) categories Investigate and Confront show higher indexes of agreement, and a greater proportion of them in the set of categorized verbalizations explain the best indexes of agreement reached; c) the process of assessing agreement through a comparison of categorizations of two participants may result in indexes that do not reflect the quality of the system of categorization. Characteristics of the categorized material, as well as of the categorizing process are mentioned as obstacles to indexes of agreement higher than $70 \%$. They also suggest that methodological features may account for high indexes found in some studies.
\end{abstract}

Key-words: Behavior-analytic therapy, Therapists' verbal behavior, Categorization of verbalizations.

1 Trabalho parcialmente financiado pelo Conselho Nacional de Desenvolvimento Científico e Tecnológico - CNPq (Processos 520062/98-1, 503717/2004-5, 305743/2004-0 e 470802/2004-9 e Programa PIBIC/UFPA) e pela CAPES (Bolsas de Mestrado e Doutorado).

2 E-mail: tourinho@amazon.com.br 
O presente artigo relata estudos desenvolvidos pelo grupo de pesquisa Análise do Comportamento: História, Conceitos e Aplicações, com vistas ao desenvolvimento de um método para análise de verbalizações (respostas verbais vocais) de terapeutas e clientes. Ele complementa outros relatos do grupo (Azevedo, 2001; Maciel, 2004; Martins, 1999; Medeiros, 2001; Oliveira-Silva \& Tourinho, 2006; Souza Filho, 2001), que também serão referidos ao longo da exposição. As investigações focalizam a relação terapêutica e algumas de suas possíveis regularidades, mas apenas do ponto de vista do comportamento verbal vocal de terapeutas (principalmente) e clientes. Apesar da referência ao comportamento verbal, a expressão "verbalizações" prevalece nos relatos como forma de reconhecer a dificuldade em estabelecer com razoável precisão as variáveis das quais as respostas verbais são função, portanto a dificuldade em falar de relações comportamentais (ou comportamentos) verbais.

Algumas dificuldades enfrentadas no início dos estudos explicam, em grande medida, o percurso seguido e os limites do que foi possível alcançar. Uma primeira dificuldade consistiu da inexistência de estudos em terapia analítico-comportamental que se ocupassem de um exame sistemático da interação verbal terapeuta-cliente e que pudessem prover uma referência inicial para as investigações, uma lacuna que até hoje subsiste na literatura estrangeira e que, há menos de uma década, começou a ser preenchida na produção brasileira. Outro problema não menos importante tem sido o acesso restrito a registros de sessões terapêuticas, decorrente de vários fatores, principalmente do receio de exposição de terapeutas e clientes e da falta de cooperação e de identificação de algumas clínicas-escola com a atividade de pesquisa (ainda que inseridas em ambientes acadêmicos).

Estudos sobre a interação verbal terapeuta-cliente justificam-se, na terapia analítico-comportamental, tanto mais quanto avança, em particular no Brasil, um modelo de intervenção descrito como terapia verbal face a face. Na última década ou pouco mais, esse avanço tem dado origem à preocupação com os vínculos da intervenção verbal com princípios conceituais e filosóficos da análise do comportamento (cf. Cavalcante, 1999; Dougher, 1993, 1994; Dougher \& Hayes, 1999). Talvez o avanço dessa modalidade de intervenção signifique (ou deva significar - cf. Guedes, 1993) um menor afastamento da tradicional modificação do comportamento do que às vezes é sugerido, mas, inegavelmente, institui uma necessidade de descrição e análise do que se passa na intervenção, que apenas começa a ser respondida.

O estudo realizado por Martins (1999), que tomou como referência inicial os trabalhos de Margotto (1998), Kovac (1999) e Zamignani (1999), deu origem a um esforço para a especificação de regularidades nas verbalizações em terapia por meio da elaboração e uso de categorias que as sintetizassem. $\mathrm{O}$ estudo, voltado principalmente para verbalizações que abordavam eventos privados, evidenciou a necessidade de diferenciar categorias (genéricas) pertinentes à análise de qualquer situação de atendimento clínico (por exemplo, "investigação", "conselhos", "feedback") de categorias que diziam respeito a dimensões só justificadas face a um problema de pesquisa particular (por exemplo, "referências a eventos privados como causa de eventos comportamentais"). As primeiras passaram a ser denominadas "categorias de registro"; as últimas, "categorias de análise". Mais tarde (e.g., Maciel, 2004), as "categorias de registro" de verbalizações de terapeutas passaram a ser denominadas "categorias relativas às funções básicas das verbalizações de terapeutas" e as categorias de análise de verbalizações de terapeutas e clientes foram denominadas "categorias relativas a dimensões específicas das verbalizações de terapeutas" e "categorias relativas a dimensões específicas das verbalizações de clientes".

Já na pesquisa de Martins (1999), ficou evidente a impossibilidade de especificação das relações funcionais entre verbalizações 
de terapeutas e clientes, ainda que conjuntos amplos de informações sugerissem alguns prováveis controles das verbalizações de uns pelas verbalizações dos outros. Possíveis controles desse tipo vieram a ser objeto de uma análise mais sistemática no trabalho de Maciel (2004), comentado adiante.

O estudo realizado por Souza Filho (2001) merece um detalhamento das categorias empregadas, por razões que serão esclarecidas adiante. A pesquisa se ocupou de um problema na área de habilidades sociais, com os objetivos específicos de "identificar, nas verbalizações do terapeuta, referências aos controles ambientais do comportamento passivo e do comportamento assertivo" e "analisar a forma como são abordados pelo terapeuta os aspectos topográficos e funcionais do comportamento assertivo/passivo/ agressivo" (Souza Filho, p. 38). As categorias de registro empregadas foram: Informação, Investigação, Feedback, Conselhos/Regras, Inferências, Explicações e Outras Verbalizações. Já as categorias de análise, utilizadas no exame de verbalizações que faziam referência a assertividade/passividade/agressividade, incluíam: Explicações Internalistas, Explicações Externalistas, Topografia, Estimulação Aversiva, Produção de Reforçamento, Discriminação, Generalização e Outras. Este foi o primeiro trabalho do grupo em que foi possível formular com clareza a distinção entre categorias de registro e categorias de análise, utilizando cada conjunto para o exame de dimensões diferentes da interação verbal terapeuta-cliente.

Em uma iniciativa que ilustra a possibilidade de um intercâmbio produtivo entre grupos de pesquisa sediados em instituições diferentes, Kovac (2001) conduziu, na Pontifícia Universidade Católica de São Paulo (PUC-SP), uma avaliação das categorias de registro empregadas por Souza Filho (2001) na Universidade Federal do Pará (UFPA). No estudo de Kovac, as verbalizações de terapeuta e cliente, em duas sessões de atendimento, foram categorizadas de modo independente por duas pesquisadoras, com base nas categorias de registro descritas por Souza Filho.
Outros dois pesquisadores categorizaram as mesmas transcrições com base nos operantes verbais descritos por Skinner (1957). Em seguida, foi calculado o índice de concordância entre pesquisadores. Para as categorias descritas por Souza Filho, foram alcançados índices de concordância de 74,89\% para as verbalizações do terapeuta, e 67,66\% para as verbalizações do cliente. Na categorização baseada nos operantes verbais de Skinner, o índice de concordância foi de 73,62\%, tanto para as verbalizações do terapeuta quanto para as verbalizações do cliente. Esses resultados sugeriam uma certa limitação das categorias que vinham sendo empregadas (e também dos operantes verbais de Skinner), que precisaria ser equacionada.

A princípio, considerou-se que o baixo índice de concordância encontrado por Kovac (2001) poderia ser resultante de falta de treino dos pesquisadores que efetuaram a categorização, e/ou insuficiência da descrição das categorias, e/ou inadequação do sistema de categorização. Essas três hipóteses passaram a orientar algumas das investigações relatadas adiante. Enquanto isso, um outro trabalho de avaliação das categorias descritas por Souza Filho (2001) foi concluído na PUC-SP (Chequer, 2002).

No estudo de Chequer (2002), terapeutas foram solicitados a categorizar sessões de atendimento clínico, empregando as categorias de registro relatadas por Souza Filho. Os índices de concordância entre o julgamento de cada um dos participantes (três terapeutas) e um gabarito elaborado pelo pesquisador para as verbalizações do terapeuta variaram de 40,54\% a 60,08\% (índices próximos a esses foram também encontrados para verbalizações de clientes). Dentre as variáveis que poderiam explicar os baixos índices de concordância, Chequer faz referência ao seu procedimento (que permitia que o terapeuta realizasse o trabalho de forma intermitente - o terapeuta recebia um arquivo por e-mail e tinha um prazo para remeter o trabalho de categorização) e o instrumento utilizado (software para acesso à transcrição e inserção 
dos dados de categorização). Chequer também menciona as definições de categorias de Souza Filho, concordando com Kovac (2001), para quem poderia haver uma "fragilidade na definição das categorias" (p. 50). Nas palavras de Chequer (2002), as categorias de Souza Filho "são amplas e generalistas" (p. 80).

No mesmo período de realização da pesquisa de Souza Filho (2001), dois outros estudos (Azevedo, 2001; Medeiros, 2001) foram conduzidos pelo grupo da UFPA. Azevedo examinou verbalizações sobre eventos privados e seus resultados ensinaram, entre outros: que verbalizações do terapeuta com "topografias mentalistas" (e.g. "cada um tem uma força interior que permite a mudança") não significam necessariamente intervenções de caráter mentalista, mas um modo de usar a linguagem coloquial para favorecer o responder e o contato com contingências relevantes (nesse caso, não seriam tatos, mas mandos - ver, a propósito desse exemplo, a discussão de Hayes, Strosahl \& Wilson, 1999, sobre o "compromisso" como parte de uma técnica terapêutica); e é possível pensar em categorias de registro baseadas nas funções das verbalizações, mas categorias de análise invariavelmente têm uma referência topográfica. Atualmente, é necessário reconhecer que mesmo com respeito às Categorias Relativas às Funções Básicas das Verbalizações de Terapeutas (antigas categorias de registro), a definição pode ser funcional, mas a identificação e categorização apóiam-se (pelo menos parcialmente) na topografia da verbalização. O que justifica essa deliberada aceitação de uma referência topográfica para a categorização é, primeiro, o fato de que membros de uma mesma comunidade verbal reconhecem que freqüentemente há certa correspondência entre certas topografias e certas funções (e.g., "fale-me sobre a sua semana" tem usualmente a função de produzir informações sobre a vida recente do cliente, mesmo quando é seguida por verbalizações do cliente sobre seus planos futuros); segundo, as relações de contingência que confirmariam as funções não estão sempre acessíveis, especialmente porque o responder verbal mantém-se por reforço intermitente. Observe-se que não se trata, no caso das categorias de registro, ou relativas às funções básicas de verbalizações de terapeutas, de trabalhar com categorias que se definem pela topografia - a definição é sempre funcional -, mas que em muitas circunstâncias são identificadas com base apenas na topografia da verbalização (supondo-se, aqui, uma consistente correlação topografia-função).

Com o estudo de Medeiros (2001), que também focalizou verbalizações sobre eventos privados, tornou-se evidente a necessidade de levar em conta duas variáveis ao trabalhar com as categorizações de verbalizações: a experiência do terapeuta, pois certos processos não podem ser adequadamente estudados quando os participantes do estudo são terapeutas iniciantes (aqueles que mais freqüentemente atendem em clínicas-escola, onde é mais provável obter-se acesso a registros de sessões), que tendem a ficar menos sob controle do que ocorre na sessão e mais sob controle de orientações do supervisor (cf. Banaco, 1993); e a variabilidade da freqüência de categorias em cada sessão ao longo do processo de atendimento (que tendem a afetar a fidedignidade das categorizações, como se verá adiante).

Em um dos trabalhos mais recentes (Maciel, 2004), a interação verbal terapeutacliente foi examinada focalizando-se a evolução de uma queixa de ansiedade. Esse estudo mostrou que é possível articular de modo produtivo os dados produzidos com os sistemas de categorização referidos anteriormente ("categorias relativas às funções básicas das verbalizações de terapeutas", "categorias relativas a dimensões específicas das verbalizações de terapeutas" e "categorias relativas a dimensões específicas das verbalizações de clientes") com outros tipos de medidas do que se passa no processo de atendimento, em particular com "indicadores de mudança do cliente", como formulados por Yano (2003). Por outro lado, é forçoso reconhecer que há um descompasso entre a enorme quantidade de trabalho analítico envolvido naquelas ca- 
tegorizações e as limitadas conclusões possíveis sobre o processo de mudança na terapia. Ainda assim, a construção de um sistema de categorização das funções básicas das verbalizações do terapeuta continuou sendo buscada, com a suposição de que constitui um dos poucos modos de descrever (com alguma preocupação funcional) o que de fato se passa na terapia.

Além da diferenciação entre "categorias relativas às funções básicas de verbalizações" e "categorias relativas a dimensões específicas de verbalizações", concluiu-se, ao longo dos estudos mencionados, que as verbalizações de terapeuta e cliente merecem tratamentos diferenciados. (Utilizando-se, para o cliente, as mesmas categorias empregadas na análise de verbalizações do terapeuta, chega-se a uma concentração de até $90 \%$ de verbalizações do cliente como do tipo "Informação", o que demonstra que aquele sistema de categorias pouco acrescenta à análise de verbalizações do cliente - cf. Medeiros, 2001). Decidiu-se, então, avançar inicialmente na investigação de um único conjunto de categorias, aquele relativo às funções básicas das verbalizações de terapeutas.

Os estudos descritos a seguir tiveram o objetivo de avaliar certas condições de treino e um sistema de categorização de verbalizações de terapeutas, baseado em possíveis funções básicas dessas verbalizações. Tendo em vista as hipóteses formuladas para explicar o baixo índice de concordância encontrado por Kovac (2001) e Chequer (2002), foram programados estudos que focalizaram tipo e quantidade de treino dos pesquisadores e as categorias empregadas (definição do sistema de categorias e descrição de cada categoria). Nesses novos estudos, foi empregado um procedimento de "treino continuado de pesquisadores", testado por Garcia, Azeredo, Azevedo e Tourinho (2001). Nesse procedimento, os responsáveis pela categorização recebiam instruções sobre a atividade de categorizar, antes da análise das transcrições. Após a transcrição de cada sessão, os categorizadores recebiam feedback e participavam de uma reunião para discussão das discordâncias e esclarecimento de dúvidas. Os resultados de Garcia e cols. mostraram um índice de concordância que variou de $47 \%$ a $78 \%$ (média de $72 \%$, acima do índice encontrado por Kovac para verbalizações de cliente) à medida que avançava o número de sessões categorizadas. O estudo conclui afirmando que o treino continuado pode promover percentuais mais elevados de concordância, embora não tenha se mostrado suficiente para solucionar os problemas apontados por Kovac.

Foram cinco os estudos realizados com o procedimento de treino continuado dos pesquisadores e revisão das categorias relativas às funções básicas de verbalizações de terapeutas. As categorias empregadas por Souza Filho (2001), avaliadas por Kovac (2001) e Chequer (2003) foram, portanto, alteradas, conforme descrição a seguir.

\section{Método Geral}

Participantes: variável a cada estudo.

Material: Em todos os estudos, os participantes recebiam para categorização transcrições de sessões de atendimento clínico. As sessões analisadas haviam sido realizadas por terapeutas comportamentais que tinham concluído o curso de Formação de Psicólogo, ou estagiários cursando Estágio Supervisionado em Psicologia Clínica, abordagem comportamental; os clientes eram usuários de serviços oferecidos por clínicas-escola. As sessões haviam sido registradas com gravadores de áudio e depois transcritas. A gravação das sessões foi sempre precedida de consulta e obtenção de consentimento informado por parte de terapeuta e cliente. Ao realizarem a categorização, os pesquisadores tinham acesso à transcrição integral da sessão, incluindo as verbalizações do cliente. As sessões eram transcritas cursivamente, identificando-se e numerando-se as verbalizações de terapeuta e cliente. Considerou-se que cada verbalização de um participante era delimitada pela verbalização anterior e pela verbalização sub- 
seqüente do interlocutor. Uma verbalização poderia, portanto, conter vários períodos. As verbalizações eram numeradas, obedecendo-se o fluxo da interação terapeuta-cliente (T1-C1-T2-C2...). As sessões analisadas eram sessões seguidas ou intercaladas.

Procedimento de coleta de dados: Os participantes sempre categorizavam as sessões de modo independente um do(s) outro(s). A discussão de suas categorizações acontecia individualmente ou coletivamente, dependendo do estudo. Os participantes eram informados de que, em uma verbalização, cada período poderia corresponder a uma categoria. Assim, o número de categorias poderia ser superior ao número de verbalizações. Porém, como as categorias pretendem ser excludentes, um período poderia corresponder a apenas uma categoria. O resultado da categorização informava quais categorias ocorreram em cada verbalização, mas não o número de ocorrências de cada categoria em uma verbalização. Portanto, a freqüência de uma categoria é informativa do número de verbalizações nas quais ela aparece.

Procedimento de análise de dados: Os dados foram analisados comparando-se as categorizações dos participantes, as de uns com as dos outros, ou todas com um gabarito previamente definido, dependendo do estudo. Aferiu-se, em seguida, o índice de concordância entre categorizadores (geral e por categoria), utilizando-se as fórmulas:

$$
\begin{gathered}
\mathrm{ICG}=\left(\mathrm{N}^{\circ} \text { de concordâncias } \times 100\right) / \\
\text { total de ocorrências das categorias. } \\
\mathrm{ICC} A=\left(\mathrm{N}^{\circ} \text { de concordâncias da categoria } A \times 100\right) / \\
\text { total de ocorrências da categoria } A
\end{gathered}
$$

Em que:

ICG é o Índice de Concordância Geral ICCA é o Índice de Concordância da Categoria $A$.

Nos parágrafos seguintes, são informados, para cada estudo realizado, a variá- vel manipulada, os participantes, o número de sessões categorizadas, as categorias empregadas, a variação no procedimento de coleta de dados, os resultados e a discussão. $\mathrm{O}$ sistema de categorias empregado no último estudo (Estudo 5), no formato como foi disponibilizado aos categorizadores (com introdução, lista das categorias e esclarecimentos), é apresentado no Anexo I ${ }^{3}$.

\section{Estudo 1}

Variável manipulada: revisão do sistema de categorização (excluídas as categorias "Conselho/Regras" e "Explicações", de Souza Filho, 2001; incluídas as categorias "Conselhos", "Recuperação" e "Verbalizações Mínimas"). A revisão fundamentou-se nas críticas de Kovac (2001) e Chequer (2002) ao sistema de categorização descrito por Souza Filho, bem como na conclusão, a partir do estudo de Azevedo (2001), de que mesmo categorias que remetem à funcionalidade das verbalizações podem conter, em sua definição, indicações de topografias.

Participantes: dois pesquisadores com experiência de categorização.

Número de sessões categorizadas: 4 (sessões 22, 23, 28 e 33). No caso desse estudo, foram categorizadas apenas verbalizações que faziam referência a eventos privados.

Categorias empregadas: Investigação (INV), Inferências (IFR), Informação, (IFO) Recuperação (REC), Verbalizações Mínimas (MIN), Conselho (CON), Feedback (FBK), Outras Verbalizações (OUT).

Variação no procedimento de coleta de dados: a discussão das categorizações aconteceu coletivamente.

Resultados: foi encontrado um índice médio de

3 Apresentações preliminares desses resultados encontram-se em Brandão (2002 [Estudo 1]), Souza (2004 [Estudo 2]), Garcia e Tourinho (2004 [Estudo 3]), Lima (2005 [Estudo 4]) e Batista (2006 [Estudo 5]). 
concordância entre pesquisadores de $72,75 \%$. A Figura 1, a seguir, apresenta a evolução dos índices ao longo da categorização. Observase que um índice muito baixo de concordância foi alcançado na primeira sessão categorizada. Os índices evoluíram positivamente nas transcrições seguintes, alcançando um patamar acima de $90 \%$ na última sessão categorizada.

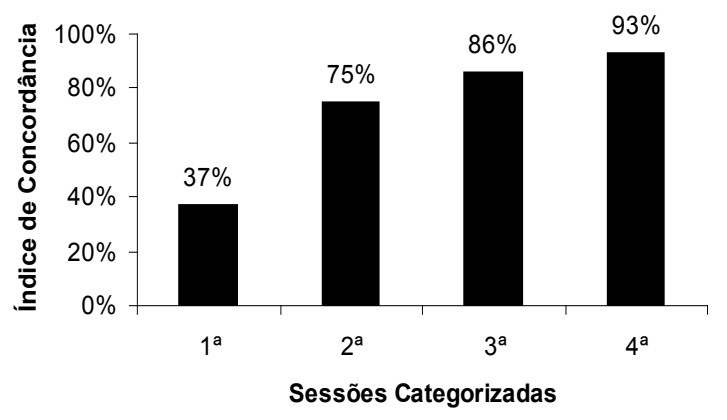

Figura 1. Índice de concordância entre pesquisadores, por sessão.

O índice de concordância por categorias mostra uma variação considerável, de 33\% (OUT) a $88 \%$ (INV), o que sugere uma consistência ou adequação variável dentre as categorias. Os dados são apresentados na Figura 2, a seguir.

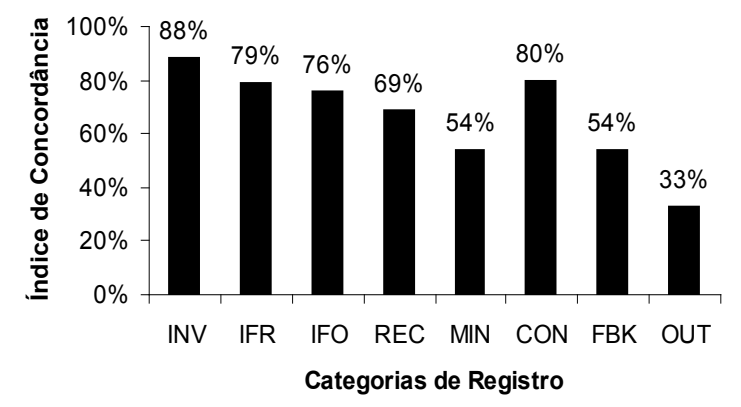

Figura 2. Índice de concordância entre pesquisadores, por categoria de registro.

Os dados relativos à evolução da concordância ao longo das sessões por categoria mostram que para cada uma delas predominou uma tendência à elevação dos índices de con- cordância. Esses dados são apresentados na Figura 3, a seguir.

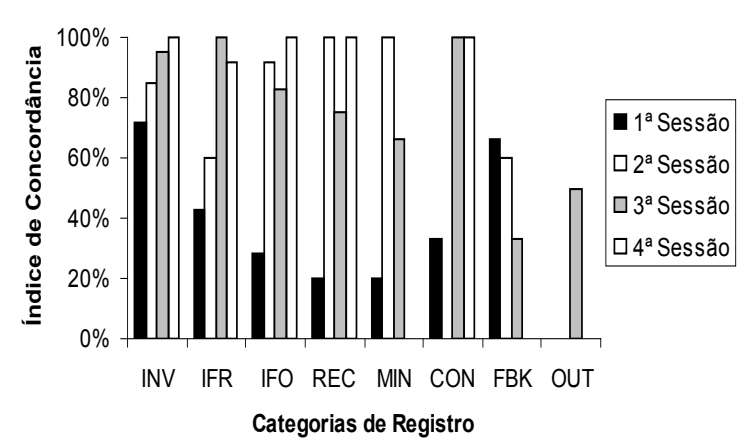

Figura 3. Índice de concordância entre pesquisadores, por categoria de registro, ao longo das quatro sessões categorizadas.

O baixo índice de concordância para algumas categorias, em algumas sessões, está associado, em geral, a uma baixa freqüência da categoria na sessão correspondente. O Quadro 1, a seguir, permite visualizar esses dados. $\mathrm{Ob}$ serve-se que os $33 \%$ de concordância da categoria OUT foram apurados a partir de apenas três ocorrências da categoria. Isto é, quanto mais baixa a freqüência de uma categoria, maior impacto tem uma discordância de categorização sobre o índice de concordância.

Discussão: o baixo índice de concordância encontrado na primeira sessão possivelmente decorreu da falta de familiaridade dos pesquisadores com o caso clínico sob exame e com o novo sistema de categorias empregado. $\mathrm{O}$ alto índice de concordância na última sessão categorizada sugere que o treino é suficiente para promover índices elevados de concordância, e que a familiaridade crescente com o caso clínico e com o sistema de categorização favorecem índices de concordância mais elevados. Um índice de concordância elevado na categorização da sessão como um todo não significa uma consistência de todo o conjunto de categorias, porém, os dados sugerem que o treino favorece categorizações mais consistentes para todas. 


\section{Tourinho e cols}

Quadro 1. Freqüência de categorias e índice de concordância entre os pesquisadores, por categoria de registro, ao longo das sessões.

\begin{tabular}{|c|c|c|c|c|c|c|c|c|c|c|}
\hline \multirow{2}{*}{ Categorias } & \multicolumn{2}{|c|}{$1^{\mathrm{a}}$ Sessão } & \multicolumn{2}{|c|}{$2^{\mathrm{a}}$ Sessão } & \multicolumn{2}{|c|}{$3^{\mathrm{a}}$ Sessão } & \multicolumn{2}{|c|}{$4^{\mathrm{a}}$ Sessão } & \multicolumn{2}{|c|}{ Total } \\
\hline & $\mathrm{N}^{0}$ & $\%$ & $\mathrm{~N}^{\mathrm{o}}$ & $\%$ & $\mathrm{~N}^{\mathrm{o}}$ & $\%$ & $\mathrm{~N}^{0}$ & $\%$ & $\mathrm{~N}^{0}$ & $\%$ \\
\hline INV & $8 / 11$ & $72 \%$ & $11 / 13$ & $85 \%$ & $18 / 19$ & $95 \%$ & $8 / 8$ & $100 \%$ & $45 / 51$ & $88 \%$ \\
\hline IFR & $3 / 7$ & $43 \%$ & $3 / 5$ & $60 \%$ & $10 / 10$ & $100 \%$ & $11 / 12$ & $92 \%$ & $27 / 34$ & $79 \%$ \\
\hline IFO & $2 / 7$ & $28 \%$ & $13 / 14$ & $92 \%$ & $5 / 6$ & $83 \%$ & $2 / 2$ & $100 \%$ & $22 / 29$ & $76 \%$ \\
\hline REC & $1 / 5$ & $20 \%$ & $6 / 6$ & $100 \%$ & $3 / 4$ & $75 \%$ & $1 / 1$ & $100 \%$ & $11 / 16$ & $69 \%$ \\
\hline MIN & $1 / 5$ & $20 \%$ & $3 / 3$ & $100 \%$ & $2 / 3$ & $66 \%$ & - & - & $6 / 11$ & $54 \%$ \\
\hline $\mathrm{CON}$ & $1 / 3$ & $33 \%$ & $2 / 0$ & $0 \%$ & $4 / 4$ & $100 \%$ & $3 / 3$ & $100 \%$ & $8 / 10$ & $80 \%$ \\
\hline FBK & $2 / 3$ & $66 \%$ & $3 / 5$ & $60 \%$ & $1 / 3$ & $33 \%$ & - & - & $6 / 11$ & $54 \%$ \\
\hline OUT & - & - & - & - & $1 / 2$ & $50 \%$ & $0 / 1$ & 0 & $1 / 3$ & $33 \%$ \\
\hline
\end{tabular}

\section{Estudo 2}

Variáveis manipuladas: descrição das categorias (alterada em relação às descrições do Estudo 1) e experiência dos categorizadores. As mudanças introduzidas tiveram como referência os resultados do Estudo 1, que sugerem tanto limitações do sistema que vinha sendo empregado, quanto a relevância da experiência do pesquisador com o sistema de categorização.

Participantes: um pesquisador experiente em categorização e um pesquisador com treino de categorização de apenas quatro sessões.

Número de sessões categorizadas: 4 (sessões 2, 4, $6,7)$.

Categorias empregadas: as mesmas do Estudo 1 - Investigação (INV), Inferências (IFR), Informação, (IFO) Recuperação (REC), Verbalizações Mínimas (MIN), Conselho (CON), Feedback (FBK), Outras Verbalizações (OUT).

Variação no procedimento de coleta de dados: a discussão das categorizações aconteceu coletivamente.

Resultados: foram encontrados índices de concordância entre pesquisadores mais elevados do que no Estudo 1, ficando a média em $90,25 \%$, com menor variação da primeira para a quarta sessão categorizadas, como de- monstrado na Figura 4, a seguir. Novamente, a primeira sessão categorizada apresentou o menor índice de concordância, porém, muito superior ao índice encontrado na primeira sessão categorizada no Estudo 1.

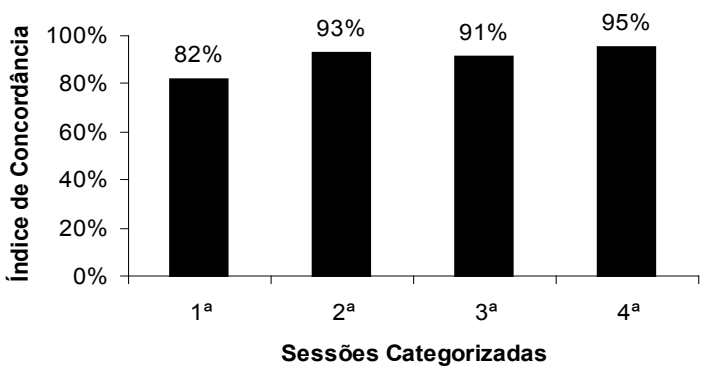

Figura 4. Índice de concordância entre pesquisadores, por sessão

Os índices de concordância por categoria mostraram-se também elevados e pouco variáveis entre as categorias. Os dados são apresentados na Figura 5, adiante.

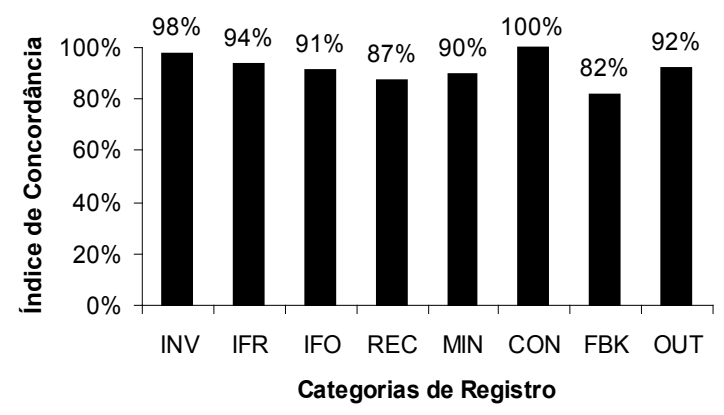

Figura 5. Índice de concordância entre pesquisadores, por categoria de registro. 
As médias elevadas não significam que não houve alterações para algumas categorias ao longo das sessões. A Figura 6, a seguir, mostra que da primeira para as demais sessões houve elevação do índice de concordância para cinco das oito categorias.

A freqüência de ocorrência das categorias novamente parece interferir com o índice de concordância. O Quadro 2, adiante, mostra que para todas as categorias (exceto uma) houve uma freqüência superior a 30 ocorrências. Observe-se, também, que a redução da concordância para a categoria IFO na terceira sessão categorizada está baseada em uma baixíssima freqüência (quatro ocorrências).

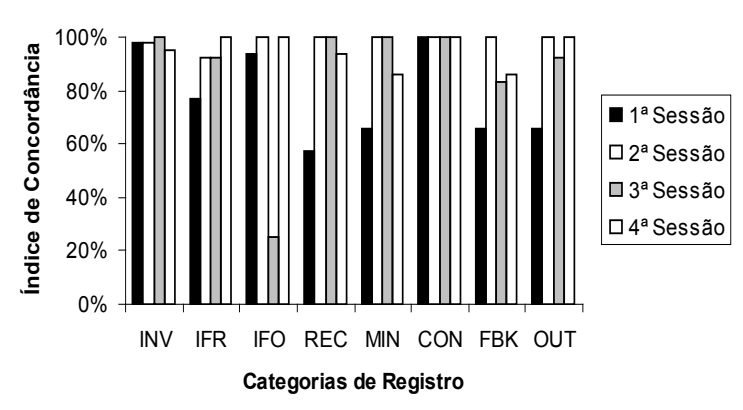

Figura 6. Índice de concordância entre pesquisadores, por categoria de registro, ao longo das quatro sessões categorizadas.

Quadro 2. Freqüência de categorias e índice de concordância entre os pesquisadores, por categoria de registro, ao longo das sessões.

\begin{tabular}{|c|c|c|c|c|c|c|c|c|c|c|}
\hline \multirow{2}{*}{ Categorias } & \multicolumn{2}{|c|}{$\mathbf{1}^{\mathbf{a}}$ Sessão } & \multicolumn{2}{c|}{$\mathbf{2}^{\mathbf{a}}$ Sessão } & \multicolumn{2}{c|}{$\mathbf{3}^{\mathbf{a}}$ Sessão } & \multicolumn{2}{c|}{$\mathbf{4}^{\mathbf{a}}$ Sessão } & \multicolumn{2}{|c|}{ Total } \\
\cline { 2 - 11 } & $\mathbf{N}^{\mathbf{0}}$ & $\mathbf{\%}$ & $\mathbf{N}^{\mathbf{0}}$ & $\mathbf{\%}$ & $\mathbf{N}^{\mathbf{0}}$ & $\mathbf{\%}$ & $\mathbf{N}^{\mathbf{0}}$ & $\mathbf{\%}$ & $\mathbf{N}^{\mathbf{0}}$ & $\mathbf{\%}$ \\
\hline INV & $50 / 51$ & $98 \%$ & $46 / 47$ & $98 \%$ & $29 / 29$ & $100 \%$ & $22 / 23$ & $95 \%$ & $147 / 150$ & $98 \%$ \\
\hline IFR & $10 / 13$ & $77 \%$ & $23 / 25$ & $92 \%$ & $23 / 25$ & $92 \%$ & $63 / 63$ & $100 \%$ & $119 / 126$ & $94 \%$ \\
\hline IFO & $15 / 16$ & $94 \%$ & $11 / 11$ & $100 \%$ & $1 / 4$ & $25 \%$ & $16 / 16$ & $100 \%$ & $43 / 47$ & $91 \%$ \\
\hline REC & $4 / 7$ & $57 \%$ & $3 / 3$ & $100 \%$ & $4 / 4$ & $100 \%$ & $16 / 17$ & $94 \%$ & $27 / 31$ & $87 \%$ \\
\hline MIN & $2 / 3$ & $66 \%$ & $4 / 4$ & $100 \%$ & $8 / 8$ & $100 \%$ & $13 / 15$ & $86 \%$ & $27 / 30$ & $90 \%$ \\
\hline CON & $1 / 1$ & $100 \%$ & $5 / 5$ & $100 \%$ & $3 / 3$ & $100 \%$ & $10 / 10$ & $100 \%$ & $19 / 19$ & $100 \%$ \\
\hline FBK & $4 / 6$ & $66 \%$ & $1 / 1$ & $100 \%$ & $5 / 6$ & $83 \%$ & $13 / 15$ & $86 \%$ & $23 / 28$ & $82 \%$ \\
\hline OUT & $4 / 6$ & $66 \%$ & $2 / 2$ & $100 \%$ & $12 / 13$ & $92 \%$ & $17 / 17$ & 100 & $35 / 38$ & $92 \%$ \\
\hline
\end{tabular}

Discussão: em linhas gerais, os resultados sugerem a suficiência do sistema de categorias e do treino realizado. Considerando-se o índice de concordância encontrado já na primeira sessão categorizada no Estudo 2, é improvável que a falta de familiaridade com o caso clínico explique o baixo índice alcançado na primeira sessão categorizada no Estudo 1. A familiaridade com o conjunto de categorias, ausente no Estudo 1 e presente no Estudo 2, parece ser uma variável de maior relevância. De todo modo, parece ser requerida uma espécie de "aquecimento" antes que os categorizadores alcancem um índice ótimo de concordância, o que já acontece na segunda sessão categorizada (observe-se que há pouca variação no índice de concordância a partir da segunda sessão categorizada). Por outro lado, considerando-se que um dos pesquisadores tinha pouca experiência, o fato de terem sido alcançados índices elevados de concordância no Estudo 2 sugere que a quantidade de experiência dos pesquisadores na atividade de categorização não é crucial. Os resultados fortalecem, ainda, a hipótese de que o índice de concordância é afetado pela freqüência das categorias. Isso acontece não só porque para categorias menos freqüentes há menores chances de feedback das categorizações (a categoria IFO já havia alcançado concordância de $87 \%$ e $100 \%$ nas duas primeiras sessões, antes de cair para $25 \%$ na terceira sessão), mas possivelmente porque ao longo da categorização de uma única sessão também acontece um tipo de "aquecimento" do categorizador. 


\section{Estudo 3}

Variável manipulada: introdução de um terceiro categorizador, cujas categorizações não haviam sido discutidas com os outros dois. Essa manipulação foi introduzida para aferir se a concordância era afetada pela familiaridade que um pesquisador tinha com o tipo de decisão do outro.

Participantes: três pesquisadores experientes, sendo que os pesquisadores 1 e 2 tinham uma história de categorização das mesmas sessões e discussão de suas categorizações um com o outro e com o coordenador da pesquisa.

Número de sessões categorizadas: 2 (sessões 1, 2).

Categorias empregadas: As mesmas dos Estudos 1 e 2 - Investigação (INV), Inferências (IFR), Informação, (IFO) Recuperação (REC), Verbalizações Minimas (MIN), Conselho (CON), Feedback (FBK), Outras Verbalizações (OUT).

Variação no procedimento de coleta de dados: os pesquisadores 1, 2 e 3 fizeram categorizações independentes. Os pesquisadores 1 e 2 tiveram suas categorizações discutidas com o terceiro categorizador após a finalização de cada uma. Dessa discussão resultou um gabarito que foi então confrontado com a categorização do pesquisador 3 .

Resultados: foram aferidas as concordâncias do pesquisador 1 com o pesquisador 2 (Figura 7) e do pesquisador 3 com o gabarito resultante da discussão das categorizações dos pesquisadores 1 e 2 (Figura 8). Os dados são apresentados a seguir.

Discussão: os dados relativos à concordância entre pesquisadores 1 e 2 fortalecem a suposição de consistência do sistema de categorização e do procedimento de treino. Mas os resultados da comparação com a categorização do pesquisador 3 sugerem que os índices elevados obtidos pelos pesquisadores 1 e 2 (assim como em outros estudos) podem resultar de uma familiaridade dos pesquisadores com o tipo de decisão um do outro. Isso porque, a despeito de todo esforço para refinar um sistema de categorizações, a complexidade do material que é colocado sob análise invariavelmente dá origem a dúvidas acerca das categorias apropriadas a cada trecho de verbalização. O categorizador, assim, está permanentemente tomando decisões sobre qual categoria atribuir a uma verbalização. Podese esperar que a decisão leve em conta algum tipo de ponderação acerca do que é mais provável que seja a função de uma verbalização do terapeuta. No entanto, quando se está familiarizado com o tipo de decisão que um outro pesquisador toma em tais circunstâncias, e quando se trata de decisões com as quais as próprias decisões serão confrontadas, é muito provável que a categorização seja afetada por aquele conhecimento.

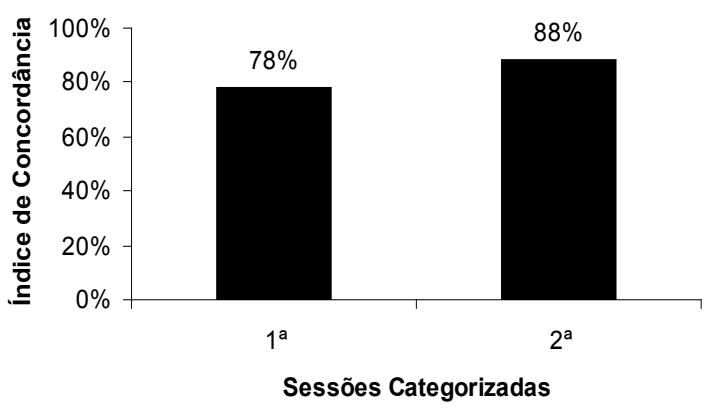

Figura 7. Índice de concordância entre os pesquisadores 1 e 2 , por sessão.

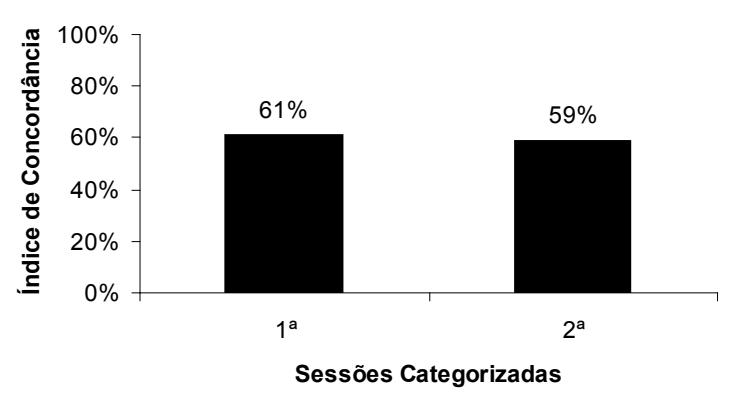

Figura 8. Índice de concordância entre o pesquisador 3 e o gabarito dos pesquisadores 1 e 2, por sessão. 


\section{Estudo 4}

Variáveis manipuladas: novo sistema de categorização e treino continuado com discussão individual das categorizações realizadas. Nesse caso, cada categorizador foi treinado em separado, sem interagir um com o outro (portanto, sem adquirir familiaridade com os tipos de decisão do outro). Em vista dos resultados do Estudo 3, buscou-se aferir a qualidade do sistema de categorização, novamente revisto, sem a interferência da familiaridade dos pesquisadores com o tipo de decisão um do outro.

Participantes: dois pesquisadores inexperientes com o procedimento de categorização.

Número de sessões categorizadas: 7 (sessões 1, 2, $5,6,7,8$ e 10).

Categorias empregadas: Informar (IFO), Investigar (INV), Dar Feedback (FBK), Confrontar (CFR), Dar Conselho (CON), Verbalizações Mínimas (MIN) e Outras Verbalizações (OUT).

Variação no procedimento de coleta de dados: discussão/treino individual das categorizações realizadas.

Resultados:

A Figura 9, a seguir, apresenta os índices de concordância entre os categorizadores. Os índices variaram de $61,78 \%$ (sessão 5) a 84,57\% (sessão 6). Embora acima de 70\% em cada sessão, à exceção da sessão 5, os índices de concordância não revelam uma consistência geral do sistema de categorização. A Figura 10, a seguir, mostra que apenas duas categorias alcançaram índices superiores a 70\%, as categorias Investigar e Confrontar.

O bom índice de concordância nas categorias Investigar e Confrontar foi suficiente para produzir um índice de concordância elevado a cada sessão, também porque a freqüência das duas categorias foi muito superior à das demais, chegando a mais de $80 \%$ de todas as ocorrências de categorias em uma sessão.

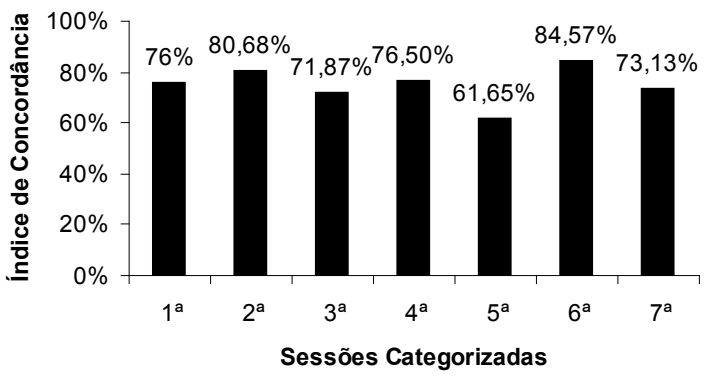

Figura 9 - Índice de concordância entre pesquisadores, por sessão.

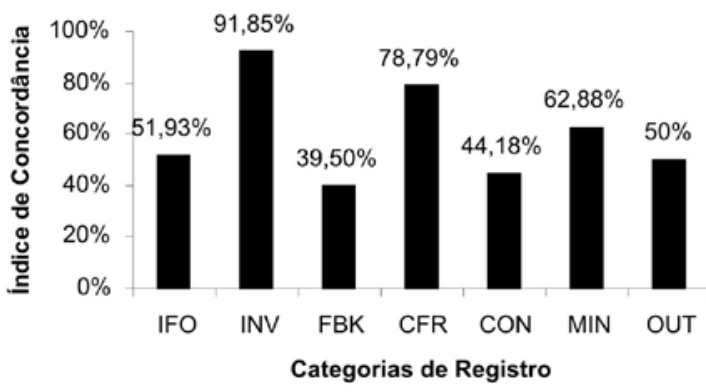

Figura 10. Índice de concordância entre pesquisadores, por categoria de registro.

Discussão: Em sessões iniciais do processo clínico, as intervenções do terapeuta são predominantemente indagações, com o fim de produzir informações novas sobre o caso (Investigar) e/ou obter confirmação ou correção de informações anteriormente prestadas pelo cliente ou de interpretações do terapeuta (Confrontar). Esses tipos de intervenção, por seu turno, são de mais fácil categorização, em razão da similaridade com o uso cotidiano do conceito "investigar". Como regra, para identificar essas categorias, o pesquisador precisa apenas decidir se a indagação ou pedido de informação diz respeito a algo já relatado ou não pelo cliente. Assim, como os dados encontrados neste estudo ilustram, categorizações de sessões iniciais do processo clínico mostram-se inapropriadas para o treinamento de categorizadores e teste dos sistemas de categorização. Para ser mais preciso, sessões de treino e teste deveriam idealmente conter uma proporção aproximada das diversas ca- 
tegorias, em um processo de avaliação de um sistema de categorização. Na ausência dessas condições, pode-se chegar a índices gerais de concordância que sugerem uma consistência e/ou suficiência do sistema de categorização e do procedimento de treino, mas que são inteiramente contrariados quando decompostos por categorias e por sessões. Finalmente, a proporção de verbalizações do tipo Investigar e Confrontar, as de mais fácil categorização, pode ser tomada como medida da complexidade das sessões, uma variável a mais a ser considerada nos estudos.

\section{Estudo 5}

Variável manipulada: complexidade das sessões e procedimento de treino. Em vista dos resultados do Estudo 4, este estudo buscou avaliar a qualidade do sistema de categorização controlando a variável complexidade da sessão, em um procedimento formatado para treino e teste dos categorizadores.

Participantes: três alunos do quarto semestre do curso de Bacharelado em Psicologia, sem histórico de participação em projetos de pesquisa semelhantes.

Número de sessões categorizadas: $5(2,5,6,7$ e 8).

Categorias empregadas: Informar (IFO), Investigar (INV), Dar Feedback (FBK), Confrontar (CFR), Dar Conselho (CON), Verbalizações Mínimas (MIN) e Outras Verbalizações (OUT).
Variação no procedimento de coleta de dados: um gabarito das sessões foi elaborado pelos pesquisadores para, com base nele, aferir a categorização realizada pelos participantes. Os participantes foram expostos a um protocolo de seis sessões de coleta de dados, que incluíam: uma sessão de Pré-Teste (PT), três sessões de Treino, ao longo das quais foram categorizadas apenas duas sessões de atendimento (TR1 e TR2), e duas sessões de Teste (TT1 e TT2). A sessão de Pré-Teste consistiu da categorização de uma sessão, mediante consulta a uma descrição das categorias, sem exemplos ou esclarecimentos. Nas sessões de treino, os participantes receberam uma descrição das categorias, que incluía exemplos e esclarecimentos sobre possíveis dúvidas. No início da sessão de TR1, um pesquisador familiarizado com o sistema de categorização fornecia explicações acerca das categorias retomando as categorizações realizadas na sessão de Pré-Teste antes do início da categorização da sessão de Treino1. Em cada sessão de Treino, este pesquisador discutia com os participantes a cada vinte verbalizações categorizadas, explicando eventuais discordâncias em relação ao gabarito. Ao longo das três sessões de Treino, duas sessões de atendimento foram categorizadas e discutidas. Nas sessões de Teste, os participantes receberam a lista com a definição das categorias com exemplos e esclarecimentos e as categorizações realizadas não foram discutidas. A variável complexidade das sessões foi estimada e foram usadas sessões com graus aproximados de complexidade para as etapas de treino e de teste (embora em cada etapa ainda existisse uma dis-

Quadro 3. Freqüência e percentual de ocorrência das categorias de registro, por etapa.

\begin{tabular}{|c|c|c|c|c|c|c|c|c|c|c|}
\hline \multirow{2}{*}{ Categorias } & \multicolumn{2}{|c|}{ PT } & \multicolumn{2}{|c|}{ TR1 } & \multicolumn{2}{c|}{ TR2 } & \multicolumn{2}{|c|}{ TT1 } & \multicolumn{2}{c|}{ TT2 } \\
\cline { 2 - 12 } & $\mathbf{N}^{\mathbf{0}}$ & $\mathbf{0}$ & $\mathbf{N}^{\mathbf{0}}$ & $\mathbf{\%}$ & $\mathbf{N}^{\mathbf{0}}$ & $\mathbf{\%}$ & $\mathbf{N}^{\mathbf{0}}$ & $\mathbf{\%}$ & $\mathbf{N}^{\mathbf{0}}$ & $\%$ \\
\hline IFO & 6 & $4,8 \%$ & 21 & $14,68 \%$ & 20 & $11,29 \%$ & 9 & $5 \%$ & 21 & $12,88 \%$ \\
\hline INV & 63 & $50,4 \%$ & 38 & $26,57 \%$ & 42 & $23,72 \%$ & 57 & $37,66 \%$ & 33 & $20,24 \%$ \\
\hline FBK & 3 & $2,4 \%$ & 11 & $7,69 \%$ & 27 & $15,25 \%$ & 21 & $11,66 \%$ & 16 & $9,81 \%$ \\
\hline CFR & 4 & $34,4 \%$ & 56 & $39,16 \%$ & 68 & $38,41 \%$ & 86 & $46,11 \%$ & 64 & $39,26 \%$ \\
\hline CON & 2 & $1,6 \%$ & 3 & $2,09 \%$ & 10 & $5,64 \%$ & 4 & $2,22 \%$ & 7 & $4,29 \%$ \\
\hline MIN & 5 & $4 \%$ & 7 & $4,89 \%$ & 6 & $3,38 \%$ & 2 & $1,11 \%$ & 12 & $7,36 \%$ \\
\hline OUT & 3 & $2,4 \%$ & 7 & $4,89 \%$ & 4 & $2,25 \%$ & 4 & $2,22 \%$ & 10 & $6,25 \%$ \\
\hline
\end{tabular}


tribuição desequilibrada das categorias, visto tratar-se de uma transcrição de sessão real). $\mathrm{O}$ Quadro 3, a seguir, informa a freqüência das categorias em cada sessão categorizada. Nas etapas de Pré-Teste, Treino 1 e Teste 1 , foram usadas sessões com maior ocorrência da categoria Investigar (consideradas sessões menos complexas) e nas etapas de Treino 2 e Teste 2 foram usadas sessões com uma distribuição maior de ocorrência das demais categorias (consideradas sessões mais complexas).

Resultados: As categorizações realizadas por cada participante foram confrontadas com o gabarito elaborado pelos pesquisadores (uma comparação entre participantes não revelou diferenças notáveis). Os resultados são apresentados nas Figuras 11, 12 e 13, a seguir. Para os três participantes, houve percentuais maiores de concordância nos treinos e nos testes comparativamente com a sessão de PT, especialmente considerando-se que, para o PT, utilizou a sessão menos complexa disponível (84,8\% das verbalizações eram do tipo Investigar ou Confrontar - apenas em uma outra sessão, TT1, a mesma soma alcançou valor aproximado). No entanto, os índices alcançados não são suficientes para se afirmar a consistência do sistema de categorização.

Para os três participantes, os índices de concordância não variam acompanhando a complexidade das sessões, mas deve-se considerar que a manipulação realizada a este respeito, por limitar-se às condições de uma sessão real, garantiram apenas um equilíbrio entre as etapas de treino e teste. Para todas as sessões categorizadas, verbalizações do tipo Informar ou Confrontar alcançaram, no gabarito, aproximadamente $60 \%$ ou mais do total de ocorrências de categorias. Na Figura 14, a seguir, encontram-se os dados de concordância por categoria, confirmando os maiores índices para aquelas categorias.

Em reunião após o encerramento da coleta de dados, os participantes do estudo mencionaram que o fato das sessões serem muito longas talvez fosse uma variável que

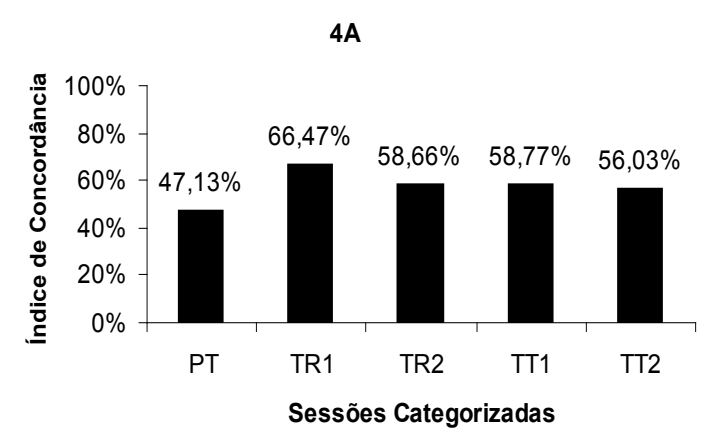

Figura 11. Índice de concordância entre o categorizador 4A e o gabarito, por sessão.

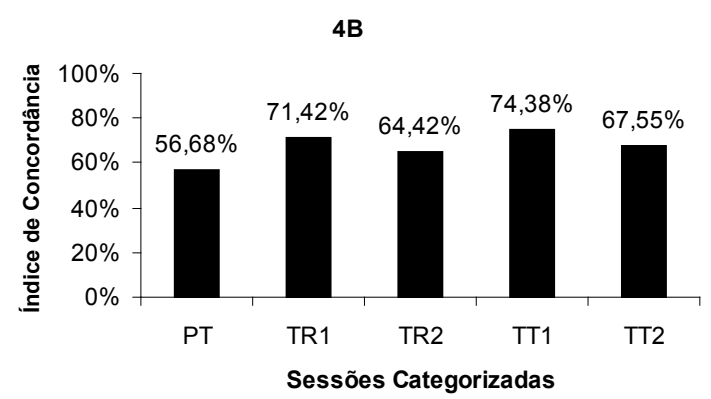

Figura 12. Índice de concordância entre o categorizador 4B e o gabarito, por sessão.

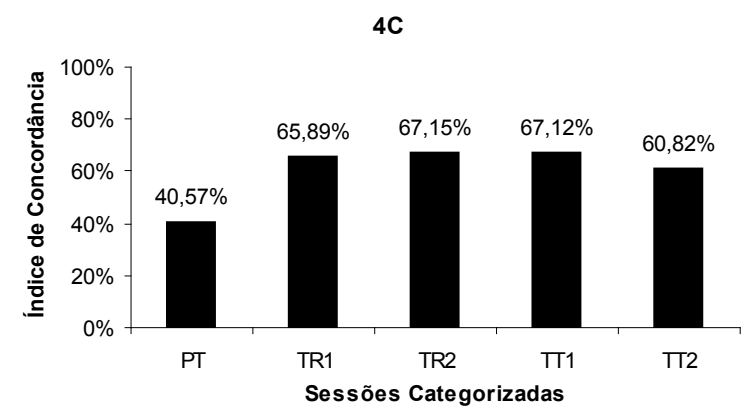

Figura 13. Índice de concordância entre o categorizador $4 \mathrm{C}$ e o gabarito, por sessão.

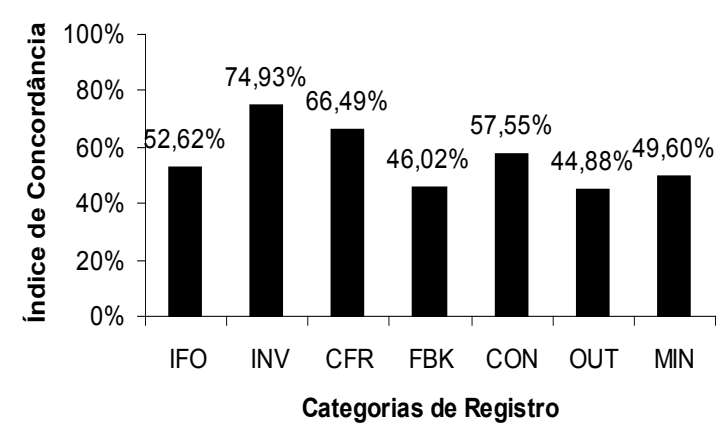

Figura 14. Índice de concordância entre pesquisadores, por categoria de registro. 
influenciaria as categorizações, em razão do cansaço produzido pela repetição da tarefa. Para averiguar essa hipótese, foram aferidos os índices de concordância por blocos (quatro) de cada sessão de atendimento. Na maioria das sessões, para a maioria dos participantes, houve uma queda dos índices de concordância no último quarto da sessão, mas os dados não foram conclusivos. Uma análise desse tipo, por outro lado, precisaria ponderar variação na complexidade ao longo da sessão.

Discussão: O treino produziu efetivamente uma elevação dos índices de concordância e a manipulação da complexidade da sessão pode ter contribuído para índices menos diferenciados por categoria do que em estudos anteriores, apesar de índices mais elevados continuarem sendo alcançados para as categorias Informar e Confrontar. A insuficiência dos índices alcançados para validar o sistema de categorização pode decorrer de limitações ainda encontradas no sistema, tanto quanto da necessidade de um treino mais extensivo, ou mais equilibrado entre as diversas categorias, o que não parece ser possível utilizandose sessões reais e/ou não editadas. A fadiga nos processos de categorização também parece ser uma variável a requerer atenção, mas no contexto de uma consideração da variação de complexidade intra-sessão. A utilização de um gabarito independente evita uma elevação artificial dos índices de concordância, sem a necessidade de um treino individualizado de categorizadores.

\section{Discussão Final}

Os estudos aqui relatados ilustram algumas dificuldades para se alcançar uma taxonomia das intervenções verbais de terapeutas em contextos de atendimento clínico, ao mesmo tempo em que sugerem algumas variáveis que merecem atenção em investigações com esse fim.

As dificuldades começam com a natureza do material com o qual é possível realizar os estudos. Transcrições de sessões revelam apenas parcialmente a intervenção do terapeuta e não contêm todas as dicas contextuais relevantes para a identificação das funções das verbalizações. Muitas vezes, participa desse contexto a história do atendimento. Analisar sessões iniciais de um caso clínico constitui um modo de prover a necessária familiaridade com o atendimento, ao mesmo tempo em que compromete o treino e o reconhecimento do conjunto variado de funções das verbalizações, dada a predominância de algumas funções nessa etapa. Prover o conhecimento de um conjunto amplo de transcrições reservando a tarefa de categorização para algumas sessões de etapas mais avançadas eleva substancialmente a quantidade de trabalho requerido, comprometendo o recrutamento de participantes, em razão da disponibilidade de tempo requerida para participar dos estudos, ou a atividade de categorização, por fadiga dos participantes.

A diversidade de funções que as verbalizações dos terapeutas assumem no contexto da sessão, assim como sua dependência de aspectos contextuais nem sempre disponíveis para análise, tornam o processo de categorização um exercício inferencial. A possibilidade de leitura do conjunto da sessão (e das sessões) para a categorização de cada verbalização é essencial, idas e vindas são a regra, e ainda assim as decisões são apenas aproximativas. $\mathrm{O}$ categorizador decide, portanto, a cada momento, o que é a função mais provável de cada verbalização, considerados os elementos que lhe são disponibilizados e o fato de que, sendo membro de uma mesma comunidade verbal, tem ciência de certas relações topografia-função. Esse fato não deve ser subestimado, nem representa, por si, uma precariedade do processo de categorização, mas suas implicações ainda requerem exame.

Os sistemas de categorização utilizados nos estudos foram sendo modificados à medida que se obtinha alguma clareza sobre as prováveis funções das verbalizações e as possíveis sobreposições das categorias usadas. Não é possível afirmar a suficiência ou 
insuficiência da última versão elaborada (cf. Anexo 1), sem uma avaliação mais sistemática de todas as outras variáveis que podem estar condicionando os índices de concordância relatados. Em qualquer caso, a apreciação dessas variáveis requererá, primeiro, que terapeutas comportamentais, em clínicas escolas e em consultórios particulares, viabilizem o acesso do pesquisador ao processo terapêutico, observados, obviamente, os requisitos éticos para tal.

Algumas das variáveis que parecem condicionar os índices de concordância incluem, além de familiaridade com o caso clínico, familiaridade diferencial com as categorias, tipo e quantidade de treino de categorização, complexidade das sessões, processo de aferição da concordância e fadiga no processo de categorização.

Talvez sejam inalcançáveis, considerando-se todos os fatores mencionados, índices de concordância superiores a $80 \%$, como os estudos têm procurado estabelecer. Quando esse índice foi ultrapassado, encontraramse aspectos que muito provavelmente o inflacionaram artificialmente. Quanto mais rigor vai sendo imprimido à avaliação dos sistemas de categorização, mais distantes vão ficando aqueles índices aspirados pelo pesquisador. De uma perspectiva realista, que leve em conta a enorme complexidade do fenômeno investigado e do processo de investigá-lo, 80\% de concordância constitui um índice para evocar desconfiança quanto aos aspectos metodológicos envolvidos.

A construção de material para treino e análise, e mesmo uma possível edição de sessões, pode mostrar-se útil enquanto estratégia exploratória para o delineamento de sistemas de categorização (taxonomias), que, no entanto, só terão sua validade efetivamente aferida quando confrontados com o material real encontrado nas interações verbais tera- peuta-cliente. Nesse momento, as variáveis mencionadas necessariamente precisarão ser objeto de análise.

Apesar das dificuldades referidas, o trabalho até aqui realizado promoveu uma aproximação às prováveis funções das verbalizações de terapeutas, integrando-se a inúmeros outros estudos desenvolvidos por outros grupos de pesquisa, e merece ter continuidade por várias razões, especialmente por duas. Primeiro, porque conhecer essas funções é essencial para investigar as condições de efetividade da terapia. Sem esclarecer exatamente o que as verbalizações do terapeuta produzem (e aqui só foram discutidas funções gerais ou básicas, isto é, funções comuns em todos os contextos de atendimento), não será possível avançar na discussão das condições para o sucesso da terapia. Segundo, sem tal conhecimento, a formação de novos terapeutas é mais difícil.

Nos estágios de formação em atendimento clínico, nas várias abordagens, não é raro encontrar-se práticas que visam muito mais à compreensão da problemática do cliente, a elaboração do caso, do que a modelagem do comportamento do terapeuta. Em parte, essa modelagem depende de um avanço na especificação das funções das verbalizações de terapeutas, apesar de basear-se em muito mais do que esse tipo de especificação.

Por fim, a importância e necessidade de uma especificação das funções de verbalizações de terapeutas no contexto de atendimento clínico não deve prevalecer indiferente à relação custo-benefício nos processos de categorização que puderem ser delineados. Não está claro como avaliar e/ou como lidar com essa dimensão do problema, mas é notório que não pode ser ignorada, sob o risco de comprometer a efetividade e relevância do trabalho realizado. 
Tourinho e cols

\section{Referências Bibliográficas}

Azevedo, Y. L. (2001). Verbalizações sobre eventos privados em terapia analítico-comportamental: Uma análise das intervenções do terapeuta. Dissertação de Mestrado. Programa de Pós-Graduação em Teoria e Pesquisa do Comportamento. Universidade Federal do Pará. Belém-PA.

Banaco, R. A. (1993). O impacto do atendimento sobre a pessoa do terapeuta. Temas em Psicologia, 2, 71-79.

Batista, J. R. (2006). Avaliação de um procedimento de treino para categorização de verbalizações de terapeutas. Trabalho de Conclusão do Curso de Bacharelado em Psicologia. Universidade Federal do Pará. Belém-PA.

Brandão, G. G. (2002). Análise de verbalizações de terapeuta e cliente em terapia analítico-comportamental: Desenvolvimento de categorias de registro. Trabalho de Conclusão do Curso de Bacharelado em Psicologia. Universidade Federal do Pará. Belém-PA.

Cavalcante, S. N. (1999). Análise funcional na terapia comportamental: uma discussão das recomendações do behaviorismo contextualista. Dissertação de Mestrado. Curso de Mestrado em Psicologia: Teoria e Pesquisa do Comportamento, Universidade Federal do Pará. Belém-PA.

Chequer, M. A. A. (2002). Estudo metodológico da medida de fidedignidade entre juízes na categorização de respostas verbais-vocais de terapeuta e cliente em duas condições de trabalho. Dissertação de Mestrado. Programa de Estudos Pós-Graduados em Psicologia Experimental: Análise do Comportamento. Pontifícia Universidade Católica de São Paulo. São Paulo-SP.

Dougher, M. J. (1993). Clinical behavior analysis. The Behavior Analyst, 16, 269-270.

Dougher, M. J. (1994). Clinical behavior analysis. The Behavior Analyst, 17, 287.

Dougher, M. \& Hayes, S. C. (1999). Clinical behavior analysis. In M. J. Dougher (Ed.), Clinical behavior analysis (pp. 11-25). Reno, Nevada: Context Press.

Garcia, M. G., Azeredo, G. G. B., Azevedo, Y. L. \& Tourinho, E. Z. (2001). Verbalizações sobre eventos privados em terapia analítico-comportamental: Uma análise de verbalizações do cliente. Resumos do X Encontro Brasileiro de Psicoterapia e Medicina Comportamental. Campinas, SP: Associação Brasileira de Psicoterapia e Medicina Comportamental, pp.76-77.

Garcia, M. G. \& Tourinho, E. Z. (2004). Análise de verbalizações de terapeutas: Validade de categorias e familiaridade entre categorizadores. Anais do XV Seminário de Iniciação Científica da Universidade Federal do Pará (p. 357). Belém: Pró-Reitoria de Pesquisa e Pós-Graduação da Universidade Federal do Pará.

Guedes, M. L. (1993). Equívocos da terapia comportamental. Temas em Psicologia, 2, 81-85.

Hayes, S. C., Strosahl, K. D. \& Wilson, K. G. (1999). Acceptance and commitment therapy: An experiential approach to behavior change. New York: Guilford Press.

Kovac, R. (1999). Um Estudo sobre as Variáveis de Controle que Podem Operar sobre o Comportamento do Terapeuta Durante uma Sessão Terapêutica: Os Eventos Encobertos tem uma Função? Projeto de Pesquisa. Programa de Estudos Pós-Graduados em Psicologia Experimental: Análise do Comportamento. Pontifícia Universidade Católica de São Paulo. São Paulo-SP.

Kovac, R. (2001). Uma comparação entre duas propostas metodológicas para a análise do registro de uma interação verbal em uma situação aplicada - o setting clínico. Dissertação de Mestrado. Programa de Estudos Pós-Graduados em Psicologia Experimental: Análise do Comportamento. Pontifícia Universidade Católica de São Paulo. São Paulo-SP.

Lima, J. B. (2005). Avaliação de um sistema para categorização de verbalizações de terapeutas. Trabalho de Conclusão do Curso de Bacharelado em Psicologia. Universidade Federal do Pará. Belém-PA.

Maciel, J. M. (2000). Terapia analítico-comportamental e ansiedade: Análise da interação verbal terapeuta-cliente. Projeto de Pesquisa. Programa de Pós-Graduação em Teoria e Pesquisa do 
Comportamento. Universidade Federal do Pará. Belém-PA.

Margotto, A. (1998). Identificando mudanças na interação verbal em situação clínica. Dissertação de Mestrado. Programa de Pós-Graduação em Psicologia. Instituto de Psicologia da Universidade de São Paulo. São Paulo-SP.

Martins, P. S. (1999). Atuação de terapeutas estagiários com relação a falas sobre eventos privados em sessões de terapia comportamental. Dissertação de Mestrado. Curso de Mestrado em Psicologia: Teoria e Pesquisa do Comportamento. Universidade Federal do Pará. Belém-PA.

Medeiros, M. L. A. (1999). Eventos privados em terapia analítico-comportamental: Uma análise de verbalizações de terapeuta e cliente. Pesquisa Supervisionada II. Programa de Pós-Graduação em Teoria e Pesquisa do Comportamento. Universidade Federal do Pará. Belém-PA.

Medeiros, M. L. A. (2001). Eventos Privados em terapia analítico-comportamental: Uma Análise de verbalizações de terapeuta e cliente. Dissertação de Mestrado. Programa de Pós-Graduação em Teoria e Pesquisa do Comportamento. Universidade Federal do Pará. Belém-PA.

Oliveira-Silva, M. C. \& Tourinho, E. Z. (no prelo). Avaliação de duas condições de treino de categorizadores de verbalizações de terapeutas. Revista Brasileira de Terapia Comportamental e Cognitiva.

Skinner, B. F. (1957). Verbal behavior. New York: Appleton-Century.

Souza Filho, R. C. (2001). Assertividade e passividade na terapia analítico-comportamental: Análise de um atendimento clínico em estágio supervisionado. Dissertação de Mestrado. Programa de Pós-Graduação em Teoria e Pesquisa do Comportamento. Universidade Federal do Pará. Belém-PA.

Souza, L. M.(2004). Relatório final de bolsa do CNPq. Trabalho não publicado. Universidade Federal do Pará. Belém-PA.

Zamignani, D. R. (1999). Consistência Teórica do Terapeuta Comportamental: Uma Comparação entre o Atendimento de Clientes com Comportamento Obsessivo-Compulsivo e Clientes com Outros Tipos de Queixa. Projeto de Pesquisa. Programa de Estudos Pós-Graduados em Psicologia Experimental: Análise do Comportamento. Pontifícia Universidade Católica de São Paulo. São Paulo-SP.

Yano, Y. (2003). Tratamento padronizado e individualizado no transtorno do pânico. Tese de Doutorado. Programa de Pós-Graduação em Psicología. Universidade de São Paulo. São Paulo-SP.

Zamignani, D. R. (2001). Uma tentativa de caracterização da prática clínica do analista do comportamento no atendimento de clientes com e sem o diagnóstico de transtorno obsessivo-compulsivo. Dissertação de Mestrado. Programa de Estudos Pós-Graduados em Psicologia Experimental: Análise do Comportamento. Pontifícia Universidade Católica de São Paulo. São Paulo-SP. 


\section{Anexo I}

\section{Categorias Relativas às Funções Básicas de Verbalizações do Terapeuta}

Apresentamos, a seguir, um sistema de categorização para a análise de verbalizações de terapeutas. Ele tem como referência as possíveis funções das verbalizações dos terapeutas no contexto da terapia. Apesar de baseadas nas funções, as descrições das categorias às vezes mencionam a forma da verbalização. Isso acontece por duas razões: a) porque sabemos que, na nossa cultura, certas formas verbais têm determinadas funções; e b) porque, às vezes, a função de uma verbalização não fica evidente no diálogo que se segue imediatamente a ela. Ao categorizar as verbalizações, deve-se atentar para alguns aspectos:

a) é importante ler a sessão inteira e considerar o contexto de cada verbalização antes de atribuir uma ou mais categorias a uma verbalização do terapeuta.

b) uma verbalização do terapeuta é constituída por toda sua fala entre a verbalização anterior e a verbalização subseqüente do cliente. Uma mesma verbalização do terapeuta pode conter ocorrências de várias categorias, mas nesse caso, cada categoria corresponderá a um período da verbalização.

c) não se precisa especificar quantas vezes uma categoria ocorre numa verbalização, mas apenas indicar quais categorias estão presentes em cada verbalização.

e) nas situações em que houver dúvidas sobre qual categoria é a mais apropriada para uma verbalização (ou período de uma verbalização), considere-se o contexto e indique-se o que seria mais provavelmente a função daquela intervenção.

As categorias são as seguintes:

Informar (IFO): Verbalizações que informam sobre aspectos do processo terapêutico, ou sobre assuntos abordados pelo cliente e pelo terapeuta. Têm a função de alterar o conhecimento do cliente sobre o processo terapêutico ou sobre assuntos mencionados por terapeuta e cliente.

Ex: "Há vários tipos de reação, reação passiva, reação agressiva...".

Atenção: Informar trata de questões abordadas nas sessões, mas sem mencionar o comportamento específico do cliente.

Investigar (INV): Verbalizações com ou sem a forma interrogativa que solicitam novas informações ao cliente. Têm a função de produzir novas informações sobre a história ambiental do cliente e ensinar o cliente a posicionar-se de uma forma investigativa diante de fatos ocorridos.

Ex: "E hoje, o que te deixa ansioso no teu trabalho atual?".

Atenção: Investigar pode não ter a forma interrogativa.

Dar Feedback (FBK): Verbalizações de aprovação, desaprovação ou correção de verbalizações específicas do cliente, qualificando de algum modo sua verbalização anterior. Têm a função de fortalecer ou enfraquecer verbalizações do cliente sobre si mesmo ou sobre aspectos de sua história ambiental.

Ex: "Isso é muito bom pra ti".

Atenção: Dar feedback não é antecedido por uma indagação do cliente.

Confrontar (CFR): Verbalizações que afirmam a ocorrência de condições, eventos ou relações entre eventos, pertinentes a questões abordadas pelo cliente, acrescidas ou não de um pedido forma de confirmação. Têm a função de confrontar o cliente com seu relato anterior, ou com 
uma compreensão/interpretação do terapeuta para os fatos/eventos relatados, produzindo confirmação ou não de sua compreensão/interpretação.

Ex: “As decisões passam sempre por você, não é?".

Atenção: Confrontar pode ser uma verbalização inteiramente interrogativa.

Dar Conselho (CON): Verbalizações que sugerem ao cliente comportar-se de determinado modo. Têm a função de prover ao cliente uma indicação de comportamento com maior probabilidade de ser reforçado.

Ex: "Você poderia num determinado momento, se tiver oportunidade, chamar ele, ou se acontecer uma outra situação desse tipo, chamar ele à parte e explicar o que tá acontecendo".

Atenção: Dar Conselho só se aplica a verbalizações nas quais o terapeuta claramente sugere ao cliente um curso de ação.

Verbalizações Mínimas (MIN): Verbalizações que sinalizam a atenção do terapeuta e/ou uma aprovação genérica do comportamento de verbalizar do cliente. Têm a função de promover a continuidade da verbalização do cliente.

Ex: "Hum hum".

Atenção: Nem toda verbalização curta é uma Verbalização Mínima.

Outras Verbalizações (OUT): Outras verbalizações do terapeuta. Tem funções diversas daquelas assinaladas acima.

Ex: "Como vai?", “Hoje o dia está realmente úmido”.

\section{Esclarecimentos e Exemplos:}

1) A categoria Informar deve ser empregada apenas quando a verbalização do terapeuta diz respeito a assuntos ligados à problemática discutida nas sessões; não inclui, portanto, informações sobre assuntos sem relação com o que foi discutido nas sessões. Alguns exemplos: "A ansiedade pode ser causada por vários fatores" (Informar); "Você pode encontrar o curso que está procurando na Universidade Federal" (Informar); "Parece que eu peguei uma boa gripe" (Outras Verbalizações); "Hoje o trânsito estava terrível" (Outras Verbalizações).

2) Na abordagem de um assunto discutido na sessão, a verbalização do terapeuta será considerada Informar quando abordar um tema de modo genérico, mas será considerada Confrontar quando abordar o que for específico do cliente. Alguns exemplos: “Certos comportamentos podem ser apropriados em uma situação, mas inadequados em outras" (Informar); "Quando você reage às provocações da sua colega, pode estar fortalecendo esse modo dela agir" (Confrontar).

3) Quando o cliente pergunta ao terapeuta se ele entendeu uma colocação sua, a resposta do terapeuta (afirmativa ou negativa) constitui uma ocorrência de Informar.

4) Algumas verbalizações que não têm a forma interrogativa têm a função de Investigar. Por exemplo, a verbalização "Conte-me como foi sua vida escolar".

5) Verbalizações curtas podem ser Dar Feedback, Informar, ou Verbalizações Mínimas. Verbalizações curtas são consideradas Dar Feedback quando dealgum modo aprovam/desaprovam a verbalização anterior do cliente (por exemplo: "Uhm hum", "Isso", "Muito bem", "Certo", após o cliente descrever uma opinião, uma compreensão ou um comportamento seus). São Informar quando respondem a uma indagação do cliente (por exemplo: “Uhm hum”, após o cliente perguntar: "Você entendeu?"). São consideradas Verbalizações Mínimas quando não qualificam a verbalização anterior do cliente, nem respondem a sua indagação, mas apenas sugerem ao cliente que continue a verbalizar (por exemplo, "Uhm hum", "Entendo", "Sei").

6) Frases interrogativas são, em geral, Investigar ou Confrontar. Uma indagação é Investigar 


\section{Tourinho e cols}

quando tem a função de produzir uma informação nova sobre a problemática do cliente, mas é Confrontar quando sua função é produzir uma confirmação pelo cliente de algo que ele já afirmou antes. Alguns exemplos: “Quando você visitou seus irmãos pela última vez?” (Investigar); "Você visitou seus irmãos no último sábado?" [após o cliente ter afirmado que visitou os irmãos no último sábado] (Confrontar).

7) Verbalizações que concluem com uma interrogação que pede confirmação são exemplos de Confrontar. Por exemplo, a verbalização “Você queria ter ido ao jogo de futebol, não é?" constitui uma ocorrência de Confrontar, pois tem a função de produzir uma confirmação ou não de uma interpretação do terapeuta (ou de uma afirmação anterior do cliente).

Informações genéricas sobre possíveis comportamentos não são exemplos de Dar Conselho, mas apenas de Informar ou Confrontar. Exemplos: "Você podia tentar chegar mais cedo em casa" (Dar Conselho); "Nas relações afetivas, a atenção é um componente muito importante" (Informar);

"Quando você chega cedo em casa, parece que os ânimos melhoram" (Confrontar).

Recebido em: 25/02/2007

Primeira decisão editorial em: 25/07/2007

Versão final em: 18/02/2008

Aceito para publicação em: 26/11/2007 